\title{
Combined Administration of ASCs and BMP-12 Promotes an M2 Macrophage Phenotype and Enhances Tendon Healing
}

\author{
Richard H. Gelberman MD, Stephen W. Linderman MPhil, Rohith Jayaram MS, \\ Anna D. Dikina PhD, Shelly Sakiyama-Elbert PhD, Eben Alsberg PhD, \\ Stavros Thomopoulos PhD, Hua Shen PhD
}

Received: 30 November 2016/Accepted: 21 April 2017/Published online: 1 May 2017

(C) The Association of Bone and Joint Surgeons (B) 2017

\begin{abstract}
Background Outcomes after intrasynovial tendon repair are highly variable. An intense inflammatory cascade followed by a delayed healing response can cause adhesion formation and repair-site failure that severely impair the function of repaired digits. No effective remedies exist to fully address these issues. Cell- and growth factor-based therapies have been shown to modulate inflammation and improve cell proliferation and matrix synthesis and therefore are promising treatment approaches for intrasynovial tendon repair.
\end{abstract}

The institutions of one or more of the authors (RHG, SSE, ST, HS, EA, SWL, and AD) have received funding, during the study period, from the National Institutes of Health, National Institute of Arthritis and Musculoskeletal and Skin Diseases (R01AR062947,

R01AR063194, F30AR069491, T32AR007505).

All ICMJE Conflict of Interest Forms for authors and Clinical Orthopaedics and Related Research ${ }^{\mathbb{R}}$ editors and board members are on file with the publication and can be viewed on request.

Each author certifies that his or her institution approved or waived approval for the human protocol for this investigation and that all investigations were conducted in conformity with ethical principles of research.

This work was done at Washington University in St Louis (St Louis, MO, USA) and the microspheres synthesis was done at Case Western Reserve University (Cleveland, OH, USA).

Electronic supplementary material The online version of this article (doi:10.1007/s11999-017-5369-7) contains supplementary material, which is available to authorized users.

R. H. Gelberman, S. W. Linderman, R. Jayaram, H. Shen ( $₫)$ Department of Orthopaedic Surgery, Washington University, 660 South Euclid, Campus Box 8233, St Louis, MO 63110, USA e-mail: hshen22@wustl.edu

S. W. Linderman

Department of Biomedical Engineering, Washington University,

St Louis, MO, USA
Questions/Purposes (1) Can autologous adipose-derived mesenchymal stromal cells (ASCs) and recombinant bone morphogenetic protein-12 (rBMP-12) be effectively delivered to an intrasynovial flexor tendon repair without adverse effects? (2) Do autologous ASCs modulate the inflammatory response after intrasynovial tendon injury and repair? (3) Does the combined application of autologous ASCs and rBMP-12 modulate the proliferative and remodeling responses after intrasynovial tendon injury and repair?

Methods Sixteen 1- to 2-year-old female canines were used in this study. Autologous ASC sheets, with and without rBMP-12, were applied to the surface of sutured flexor tendons. Fourteen days after repair, the effects of treatment were determined using quantitative PCR (six per group) for the expression of genes related to macrophage phenotype or inflammation (IL-4, CD163, VEGF, NOS2, $I L-1 B$, and $I F N G$ ), cell proliferation (CCNDI), and tendon formation (SCX, TNMD, COLIAI and COL3A1). Proteomics analysis (four per group) was performed to examine changes in tendon protein abundances. CD146 immunostaining and hematoxylin and eosin staining (four per group) were used to detect tendon stem or progenitor cells and to semiquantitatively evaluate cellularity at the tendon repair; analyses were done blinded to group.

Results Gross inspection and cell tracing showed that autologous ASCs and rBMP-12 were delivered to the flexor

\author{
A. D. Dikina, E. Alsberg \\ Department of Biomedical Engineering, Case Western Reserve \\ University, Cleveland, $\mathrm{OH}$, USA \\ S. Sakiyama-Elbert \\ Department of Biomedical Engineering, The University of Texas \\ at Austin, Austin, TX, USA
}


tendon repair site without the deleterious effects of adhesion and repair-site gap formation. Quantitative assessment of gene and protein expression showed effects of treatment: ASC-sheet treatment modulated the postrepair inflammatory response and facilitated healing by increasing regenerative M2 macrophages (M2 marker CD204, twofold of normal, p $=0.030$ ), inflammatory inhibitor (prostaglandin reductase 1 [PTRG1], 1.6-fold of normal, $\mathrm{p}=0.026$ ), and proteins involved in tendon formation (periostin [POSTN], 1.9-fold of normal, $\mathrm{p}=0.035$ ). Consistently, semiquantitative and qualitative evaluations of repaired tissue showed that ASCsheet treatment reduced mononuclear cell infiltration $(12 \%$ less than nontreated tendons, $\mathrm{p}=0.021$ ) and introduced $\mathrm{CD} 146+$ stem or progenitor cells to the repair site. The combined administration of ASCs and rBMP-12 further stimulated M2 macrophages by increasing $I L-4$ (116-fold of normal, $\mathrm{p}=0.002$ ) and led to the increase of M2 effector matrix metalloproteinase-12 involved in matrix remodeling (twofold of normal, $\mathrm{p}=0.016$ ) and reduction of a negative regulator of angiogenesis and cell migration (StAR-related lipid transfer domain protein13 [STARD13]; 84\% of normal, $\mathrm{p}=0.000$ ), thus facilitating the proliferative stage of tendon repair.

Conclusions ASCs and BMP-12 accelerated the progression of healing in the proliferative stage of tendon repair. The effects of ASCs and BMP-12 on tendon functional recovery should be evaluated in future studies.

Clinical Relevance The cell sheet approach is an effective, biocompatible, and surgeon-friendly approach for cell and growth factor delivery during tendon repair. Combined application of ASCs and BMP-12 may accelerate intrasynovial tendon healing while suppressing the adverse inflammatory response.

\section{Introduction}

While substantial advances have been made in intrasynovial flexor tendon repair and rehabilitation during the past

\section{E. Alsberg}

Department of Orthopaedic Surgery, Case Western Reserve University, Cleveland, OH, USA

E. Alsberg

The National Center for Regenerative Medicine, Case Western Reserve University, Cleveland, OH, USA

\section{S. Thomopoulos}

Department of Orthopedic Surgery, Columbia University, New York, NY, USA

S. Thomopoulos Department of Biomedical Engineering, Columbia University, New York, NY, USA
3 decades [3, 4, 16], clinical outcomes remain highly variable. An intense early inflammatory cascade followed by an insufficient tendon regenerative response has been shown to be associated with adhesion formation, tendon weakness, elongation, and repair-site failure [3, 8, 23, 31], leading to markedly impaired functional outcomes in injured digits [3, 8, 12, 16, 22, 44]. Inflammatory factors (eg, interleukin [IL]-1 $\beta$ ) were dramatically upregulated in recent in vivo large animal studies within the first 7 days after tendon suture [20, 30]. These factors stimulated the production of proteases, caused apoptosis of tendon fibroblasts, impeded the intrinsic repair process, and promoted adhesion formation [1, 13, 15, 30, 38-40, 43]. After the initial inflammatory phase of healing, proliferative and remodeling stages of repair ensue, leading to an accrual of mechanical strength at the repair site. Repair-site maturation, which is dependent on cell migration and proliferation and on the synthesis of extracellular matrix proteins $[7,9,12,19,36]$, is inherently slow owing to the paucicellular and hypovascular nature of intrasynovial tendon. Therefore, biologically based therapeutic strategies are needed to modulate inflammation and to introduce matrixproducing cells at the repair site to effectively enhance flexor tendon healing.

Our large animal studies have shown that adiposederived mesenchymal stromal cells (ASCs) can modulate inflammatory response via regulating macrophage polarization toward a proregenerative M2 phenotype and away from a classic proinflammatory M1 phenotype during the first 7 days after tendon suture [21, 30]. It is unknown if such an effect will extend to the later proliferative stage of tendon healing. On the other hand, select growth factors, such as bone morphogenetic protein-12 (BMP-12) and -14 (BMP-14), can promote cell growth and stem cell tenogenic differentiation [19, 29]. ASCs and BMP-12 in combination, therefore, has great potential for modulating inflammation and stimulating tendon regeneration. However, as biocompatible delivery systems that do not cause inflammation are lacking, the effect of such combined therapeutic strategies on tendon healing has not been properly evaluated [10, 45]. We previously developed a cell-sheet approach that successfully delivered ASCs to the tendon repair without negative effects [30]; this approach can be modified to deliver growth factors as well.

We therefore asked: (1) Can autologous ASCs and recombinant BMP-12 (rBMP-12) be effectively delivered to an intrasynovial flexor tendon repair via cell sheets without adverse effects (eg, adhesions)? (2) Do autologous ASCs modulate the inflammatory response 14 days after intrasynovial tendon injury and repair? (3) Does the combined application of autologous ASCs and rBMP-12 modulate the proliferative and remodeling responses after intrasynovial tendon injury and repair? 


\section{Materials and Methods}

\section{Study Design}

Sixteen 1- to 2-year-old female mongrel dogs $(20-30 \mathrm{~kg})$ were used in this study. The flexor digitorum profundus tendons from the 2nd and 5th digits of the right front paw of each animal were used for tendon repair. To determine the effects of autologous ASCs and BMP-12 on intrasynovial tendon repair, four experimental groups were created (32 total tendons: $16 \operatorname{dogs} \times 2$ tendons per dog; eight tendons per group). In the first group, the flexor digitorum profundus tendons were transected and repaired in Zone 2 (Repair only group). In the second group, repaired tendons were treated with autologous ASC sheets only (ASC group). In the third group, repaired tendons were treated with ASCs and unloaded microspheres (ASC+MS group) and, in the fourth group, repaired tendons were treated with ASCs plus BMP-12-loaded microspheres (ASC+BMP12 group). The corresponding left digital flexor tendons served as normal controls (Normal group). All animals were sacrificed 14 days after repair. Tendon fragments flanking the repair site (approximately $5 \mathrm{~mm}$ from each side) were subsequently collected. Of the eight repaired tendons in each repair group, four were divided longitudinally in two parts. One part was used for RNA isolation and subsequent gene expression analysis and the other was used for proteomics analysis. Two of the eight repaired tendons were divided longitudinally, with one segment used for histologic study and the other for RNA isolation and subsequent gene expression analysis. The remaining two repaired tendons were used solely for histologic study. In total, there were six samples per group designated for gene expression analysis, four samples per group designated for proteomics analysis, and four samples per group designated for histologic study.

Sustained Delivery of BMP-12 via Gelatin Microspheres

Gelatin microspheres were synthesized as previously described [32, 33]. Low $(19.5 \% \pm 5.65 \%)$ and high crosslinked $(64.9 \% \pm 9.9 \%)$ microspheres were generated by crosslinking dry microspheres in $1 \% \mathrm{w} / \mathrm{v}$ aqueous genipin solution (Wako Chemicals USA, Inc, Richmond, VA, USA) in distilled water at room temperature for 2 and 24.5 hours, respectively. To load BMP-12, lyophilized microspheres were UV-sterilized for 10 minutes and rehydrated in phosphate buffered saline (PBS) solution $(\mathrm{pH}$ 6) containing various concentrations of BMP-12 for 2 hours at $37{ }^{\circ} \mathrm{C}$. Unloaded control microspheres were soaked in PBS without BMP-12. At $\mathrm{pH}$ 6, positively charged BMP-12 and negatively charged acidic gelatin form complexes [6, 42].

To determine BMP-12 release kinetics, BMP-12 was biotinylated with EZ-Link ${ }^{\mathrm{TM}}$ Sulfo-NHS-Biotin kit (Thermo Fisher Scientific, Rockford, IL, USA) according to the manufacturer's protocol except for substituting the manufacturer's buffer with $50 \%(\mathrm{v} / \mathrm{v})$ propylene glycol containing $1 \mathrm{~mol} / \mathrm{L} \mathrm{NaCl}$ and $50 \mathrm{mmol} / \mathrm{L} \mathrm{4-(2-hydrox-}$ yethyl)-1-piperazineethanesulfonic acid (HEPES) (pH 7.0) to stabilize BMP-12. The resulting biotin-BMP-12 $(2 \mu \mathrm{g})$ was loaded to either high or low crosslinked microspheres $(1 \mathrm{mg})$ as described above. BMP-12 release from microspheres was performed in PBS ( $\mathrm{pH} 7.0$ ) at $37{ }^{\circ} \mathrm{C}$ for 2 weeks and determined by measuring BMP-12 contents in PBS at varied times via dot blot for biotin and using biotinBMP-12 as a protein standard. As most of the BMP-12 was released from the low crosslinked microspheres during the first week after loading and the high crosslinked microspheres enabled a steady 20- to 40-ng daily release of BMP-12 during a 14-day period, the high crosslinked microspheres were used in the subsequent in vivo studies.

\section{In Vivo Delivery of BMP-12 Microspheres and ASCs} with Cell Sheets

Two weeks before tendon repair, autologous ASCs were isolated from subcutaneous fat tissues and expanded in culture as described previously [29, 30]. To deliver BMP12-loaded microspheres and ASCs in vivo, high crosslinked microspheres were loaded with BMP-12 at a concentration of $4 \mu \mathrm{g}$ BMP- $12 / \mathrm{mg}$ microsphere. One $\mathrm{mg}$ of BMP-12-loaded or unloaded microspheres was added to type I collagen (Corning Inc, Bedford, MA, USA) solution ( $2 \mathrm{mg} / \mathrm{mL}, \mathrm{pH}$ 7.2). The resulting suspension was allowed to gel at $37{ }^{\circ} \mathrm{C}$ for 1 hour in a round cast to generate a thin microsphere-containing collagen sheet $(\varnothing 19 \mathrm{~mm} \times 500$ $\mu \mathrm{m}$ thick). Passage 3 ASCs were subsequently cultured on the collagen sheet at a density of 16,000 cells $/ \mathrm{cm}^{2}$ for 3 to 4 days in vitro and then applied in vivo (Fig. 1A-B) [30]. To determine the viability of ASCs in the cell sheets, ASCs were cultured on a microsphere-containing collagen sheet for 6 days and then stained with a LIVE/DEAD ${ }^{\circledR}$ CellMediated Cytotoxicity Kit (Life Technologies, Eugene, OR, USA) according to the manufacturer's instructions. Findings revealed little to no cell death of ASCs (Fig. 1C).

The bioactivity of the BMP-12-loaded microspheres was validated by examining the gene expression of ASCs cultured in the collagen sheet containing BMP-12-loaded microspheres, confirming a dose-dependent increase in the expression of the tenogenic gene SCX (Fig. 1D; see below for gene expression methods). 


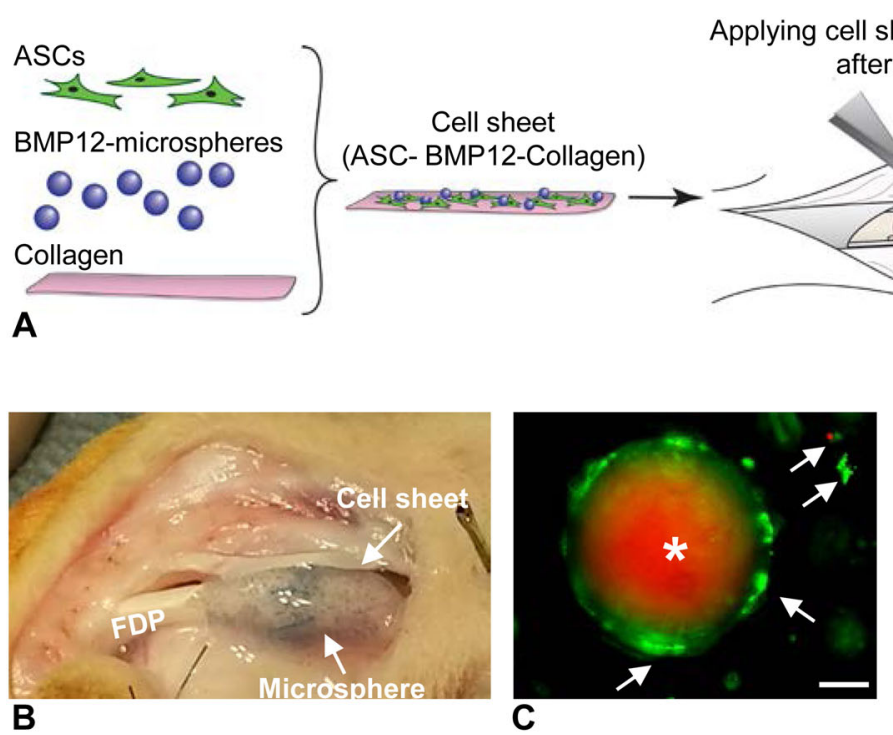

cell sheet and hyaluronic acid coat after FDP tendon repair

Fig. 1A-F Cell sheets were generated and validated for in vivo delivery of adipose-derived mesenchymal stromal cells (ASCs) and BMP12. (A) The procedures for generation and in vivo delivery of a cell sheet are illustrated. Hyaluronic acid was used to secure the cell sheet at the repair site. (B) A representative photograph shows a cell sheet applied to a repaired flexor digitorum profundus tendon (FDP). (C) A representative fluorescence image shows ASCs (arrows) and a microsphere (asterisk with red autofluorescence) in a cell sheet subjected to LIVE (green)/DEAD ${ }^{\mathbb{R}}$ (red) cell staining. Most ASCs are

To track implanted ASCs, some cell sheets were prepared with ASCs pretransduced with green fluorescent protein-expressing lentivirus. Green fluorescent proteinpositive cells, indicating the presence of ASCs, were seen along the surface and in the repair site of tendons treated with green fluorescent protein-ASCs (Fig. 1E-F; see histology methods below). There were no lipid droplets observed and there was an absence of expression of the adipogenic gene $A D I P O Q$ in ASC-treated tendons (see below for gene expression methods). These findings, which show the viability, the tenogenic response to BMP-12loaded microspheres, and the lack of adipogenic differentiation of ASCs 14 days after implantation, validate the appropriateness of the cell sheet approach for in vivo use.

\section{Gene Expression Analysis}

Gene expression in ASCs and flexor tendons was determined via quantitative reverse transcription (RT)-PCR as described previously $[29,30]$. In brief, a SYBR ${ }^{\circledR}$ Greenbased quantitative RT-PCR (Applied Biosystems, Warrington, UK) was used to assess the expression of the tenogenic gene $S C X$ in ASCs 14 days after cultured in cell sheets with BMP-12-loaded or unloaded microspheres [29]. TaqMan ${ }^{\circledR}$ RT-PCR (Applied Biosystems, Woolston, UK) was used to determine gene expression profile in repaired tendons 14 days after repair. Total RNA isolation, cDNA synthesis, and gene expression assay were performed as described previously [29, 30]. All TaqMan primers and probes used in this study were obtained from Applied Biosystems. GAPDH and PPIB were used as endogenous reference genes.

\section{Proteomics Analysis}

Protein sample preparation and quantitative proteomics analysis were performed by the Proteomics Core Lab at Washington University (supported by NIH UL1 TR000448) using a tandem-mass-tag-based assay [5]. The PROC MIXED models (SAS Institute, Cary, NC, USA) were applied to proteomics data to identify proteins differentially expressed between five different conditions (Normal, Repair only, ASC only, ASC+MS, and ASC+BMP12). Type 3 tests of fixed effects and differences of least squares means were performed to evaluate overall differential variances of proteins between groups and between every two groups. Probability values were adjusted by the false discovery rate method. Principal component analysis was performed with $\mathrm{SAS}^{\circledR} \mathrm{JMP}^{\mathbb{R}}$ pro 12 (SAS Institute). A Venn diagram was generated via a 
web-based tool, InteractiVenn (http://www.interactivenn. net) [14]. Protein functional classification was performed on selected genes using the UniProt Knowledgebase (UniProtKB) at UniProt (http://www.uniprot.org) and Panther Classification System of the Gene Ontology Reference Genome Project (http://www.pantherdb.org/about. jsp) [27].

\section{Histologic Analysis}

Serial coronal paraffin sections ( $5 \mu \mathrm{m}$ thick) were prepared from flexor tendons as previously described [30]. After deparaffinization, sections were subjected to either standard hematoxylin and eosin staining or immunofluorescence staining for tendon stem cell marker CD146 (Ab75769, 1:200 dilution; Abcam, Cambridge, MA, USA) or green fluorescent protein (A11122, 1:500 dilution; Life Technologies) as follows. Sections were treated with $0.1 \%$ trypsin (Sigma-Aldrich, St Louis, MO, USA) in PBS for 30 minutes at $37{ }^{\circ} \mathrm{C}$ and then permeabilized with $0.5 \%$ Triton $^{\mathrm{TM}} \mathrm{X}-100$ (Sigma-Aldrich) in PBS for 10 minutes. After blocking with 5\% normal donkey serum in PBS containing $0.1 \%$ Triton X-100 for 30 minutes, sections were incubated with one of the abovedescribed rabbit antibodies at the indicated dilutions at $4^{\circ} \mathrm{C}$ overnight. After thorough washing with PBS containing $0.1 \%$ Triton $\mathrm{X}-100$, the sections were incubated with Cy3labeled donkey-anti-rabbit antibodies (1:400 dilution; Jackson ImmunoResearch, West Grove, PA, USA) for 1 hour at room temperature. After washing with PBS and $0.1 \%$ Triton-X100, the sections were counterstained with bisBenzimide H33258 (Sigma-Aldrich) and mounted in a mounting medium (Vector Laboratories, Burlingame, CA, USA). Immunostainings without primary antibodies were included in parallel with each experiment to exclude nonspecific signals. Immunofluorescence images were taken with predetermined exposure time and regions of interest. The assessment of immunostainings was performed qualitatively and blinded to the treatment on two sections per sample. The cellularity at the repair site was determined by counting the number of fibroblastlike cells, polymorphonuclear cells, and mononuclear cells on hematoxylin and eosin-stained slides at a magnification of 20 at two predefined regions of interest. The results are shown as the percentage of total cell counts for each cell type.

\section{Statistics}

Unless described elsewhere, all data are shown as box plots that include median and range (minimum, 25th percentile, 75th percentile, and maximum). A one-way ANOVA followed by Student-Newman-Keuls post hoc testing (when appropriate) was performed to compare normally distributed data among groups, while ANOVA on ranks was used when data were not normally distributed. Paired Student's t-test was used to compare the repair and normal groups. The significance level was set at a probability less than 0.05 .

\section{Results}

Evaluation of Cell Sheet-mediated ASC and BMP-12 Delivery to the Tendon Repair Site

The delivery of autologous ASCs and rBMP-12 to the flexor tendon repair site was achieved without the deleterious effects of adhesion and repair-site gap formation. In four of the 32 repaired tendons, 3.0- to $3.5-\mathrm{mm}$ gap formations were noted (two animals). There were two tendons with gaps in the Repair only group, one in the ASC only group, and one in the ASC+MS group. Minor to moderate adhesions were noted in two tendons of one additional animal (one of which was in the ASC+MS group and the other in the ASC+BMP12 group). The distribution of gaps and adhesion formation was similar to that observed in prior experiments [10, 12]. All samples were included in the subsequent analyses. Histologic and proteomics analyses showed marked changes in the healing tendons compared with the uninjured controls. Histologically, increased numbers of epitenon cells were evident, with infiltration of cells in the repair site. Proteomics analysis revealed that 185 of 2287 identified proteins were differentially expressed. Principal component analysis of these proteins revealed separation of repaired samples from normal (uninjured) samples (Fig. 2A). Furthermore, repaironly samples were largely separated from ASC, ASC+MS, and ASC+BMP12 samples, and samples from the ASC group were relatively distant from those of the ASC $+\mathrm{MS}$ and ASC+BMP12 groups, indicating ASCs and BMP-12 were effective (Fig. 2A). To evaluate the overall tissue response in the proliferative stage of tendon healing, the PANTHER classification system and the UniProt Protein Knowledgebase were used to identify the function of differentially expressed proteins. One hundred fifty-nine of 185 proteins were identified and classified based on this analysis. The most active proteins in this stage were those associated with metabolic processes, extracellular matrix, and cell signaling and regulation, while only a small portion of differentially expressed proteins (14 of 185) involved in inflammation or response to injury (Fig. 2B). To further explore the effect of treatment on tendon healing, the levels of inflammation, proliferation, and remodeling in repaired tendons were evaluated by 


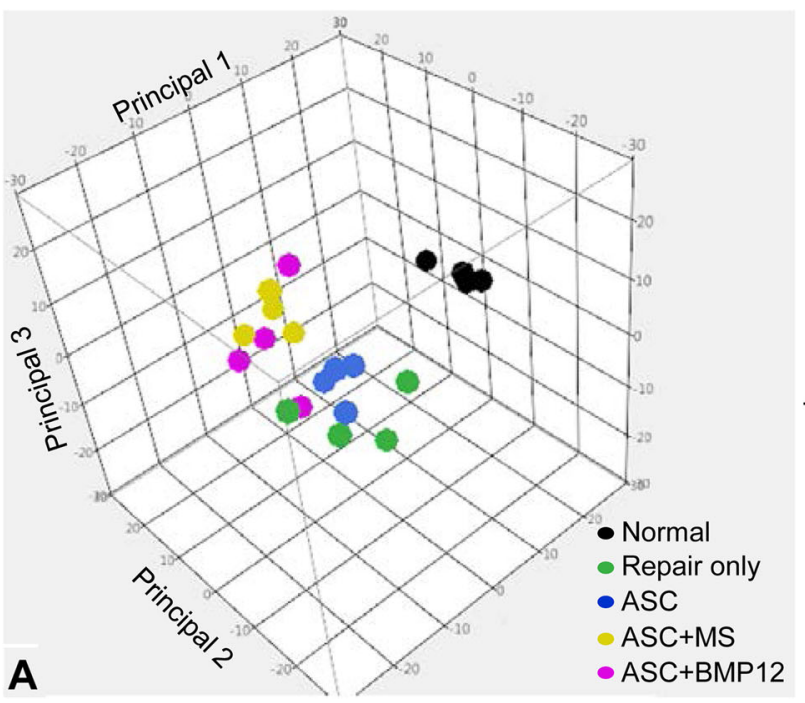

Fig. 2A-B The (A) top three principal components and (B) the functional composition of proteins differentially expressed in flexor tendons from Normal, Repair only, ASC, ASC+MS, and

comparing gene expression, proteomics, and histologic changes between treated (ASC, ASC+MS, ASC+BMP12) and nontreated (Repair only) and/or normal (Normal) tendons.

Modulation of the Inflammatory Response by ASCs and BMP-12

ASC-sheet treatment effectively modulated the postrepair inflammatory response by increasing a proregenerative and antiinflammatory M2 macrophage phenotype. At the mRNA level, nontreated tendons (Repair only) expressed higher than normal levels of proinflammatory gene NOS2 (Fig. 3A; relative mRNA abundance: paired normal, $0.0104 \pm 0.0017$; Repair only, $0.0252 \pm 0.0118$ mean difference, $-0.0148,95 \% \mathrm{CI},-0.0257$ to $-0039 ; \mathrm{p}=$ 0.041), IFNG (Fig. 3B; relative mRNA abundance: paired normal: $0.000006 \pm 0.000008$; Repair only, $0.000155 \pm$ 0.000119; mean difference, -0.000149 ; $95 \%$ CI, -0.000278 to $-0.000021 ; \mathrm{p}=0.002$ ), and $I L 1 B$ (Fig. 3C; relative mRNA abundance: paired normal, $0.0001 \pm$ 0.0001 ; Repair only: $0.0037 \pm 0.0025$; mean difference, $-0.0036 ; 95 \% \mathrm{CI},-0.0063$ to $-0.0010 ; \mathrm{p}=0.002)$. As expected, ASC treatments, either alone or in combination with BMP-12, retained tendon NOS2 level within normal range (Fig. 3A; relative mRNA abundance: paired normal, $0.0104 \pm 0.0024$; ASC, $0.0333 \pm 0.0325$; mean difference, $-0.0229 ; 95 \% \mathrm{CI},-0.0576$ to $0.0118 ; \mathrm{p}=0.394$; paired normal, $0.0086 \pm 0.0019 ;$ ASC+BMP12, $0.0092 \pm$ 0.0036; mean difference, -0.0007 ; $95 \% \mathrm{CI},-0.0056$ to $0.0043 ; \mathrm{p}=0.745$ ). IFNG (relative mRNA abundance:

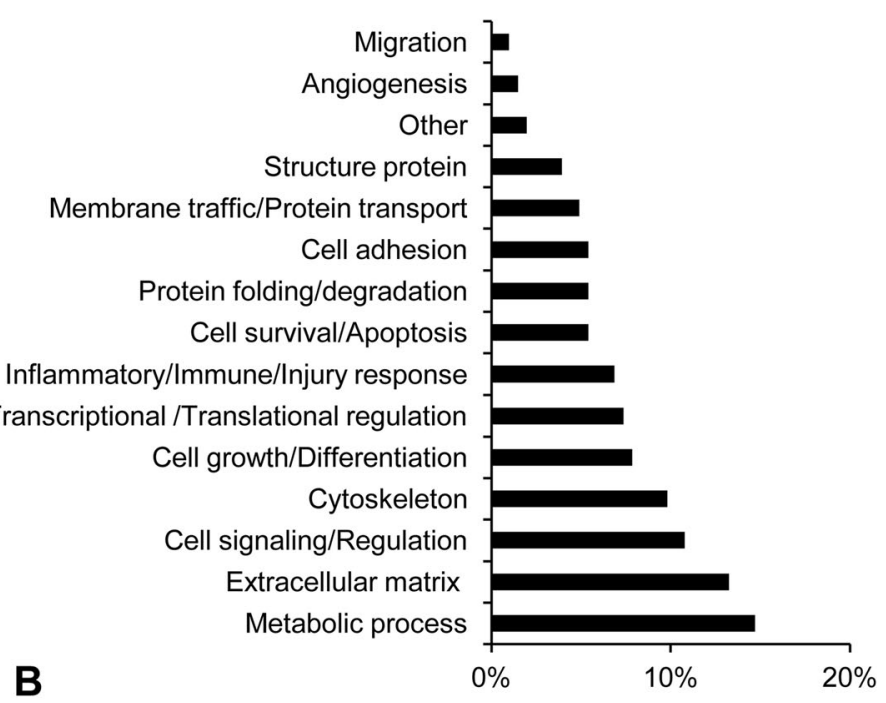

ASC+BMP12 groups are shown. ASC $=$ adipose-derived mesenchymal stromal cells; MS = unloaded microspheres.

paired normal, $0.000005 \pm 0.000006$; ASC, $0.000172 \pm$ 0.000125 ; mean difference, $-0.000167 ; 95 \%$ CI, -0.000294 to $-0.000040 ; \mathrm{p}=0.002$; paired normal, $0.000001 \pm 0.000000 ;$ ASC+BMP12, $0.000292 \pm$ 0.000227; mean difference, -0.000291; 95\% CI, -0.000529 to $-0.000053 ; \mathrm{p}=0.002$ ), and $I L 1 B$ expression levels (relative mRNA abundance: paired normal, 0.0002 \pm 0.0002 ; ASC, $0.0047 \pm 0.0028$; mean difference, $-0.0045 ; 95 \% \mathrm{CI},-0.0073$ to $-0.0017 ; \mathrm{p}=0.002$; paired normal, $0.0001 \pm 0.0000 ; \mathrm{ASC}+\mathrm{BMP} 12,0.0046 \pm$ 0.0041 ; mean difference, $-0.0045 ; 95 \% \mathrm{CI},-0.0088$ to $-0.0002 ; \mathrm{p}=0.002)$, however, were increased in all treatment groups. The relative abundance of tendon NOS2, $I F N G$, and $I L I B$ at 14 days after repair were only $3 \%, 5 \%$, and $33 \%$ of those previously reported at 7 days after repair [30], showing a substantial attenuation of tendon inflammatory response from 7 days to 14 days. The reduced effect of ASCs in regulating inflammatory gene expression likely corresponded to the changes in their biochemical environment. Consistently, no apparent difference was detected between ASC-treated (ASC) and nontreated (Repair only) tendons in the expression of antiinflammatory M2 macrophage stimulator ILA (Repair only: $4.43 \pm 7.01$; ASC: $12.24 \pm 17.43$; mean difference, $-7.82 ; 95 \% \mathrm{CI},-24.90$ to 9.27; $\mathrm{p}=0.180$; Fig 3D), M2 marker CD163 (Repair only: $3.89 \pm 1.06$; ASC: $3.70 \pm 1.23$; mean difference, 0.19; $95 \% \mathrm{CI},-1.29$ to $1.66 ; \mathrm{p}=0.784$; Fig. $3 \mathrm{E}$ ), and $\mathrm{M} 2$ effector VEGFA (Repair only: $0.96 \pm 0.49$; ASC: $1.23 \pm$ 0.79 ; mean difference $-0.26 ; 95 \% \mathrm{CI},-1.11$ to $0.58 ; \mathrm{p}=$ 0.502; Fig. 3F). Interestingly, much higher levels of IL4 (ASC+BMP12: $116.28 \pm 113.02$; mean difference between repair only and $\mathrm{ASC}+\mathrm{BMP} 12,-111.85 ; 95 \% \mathrm{CI}$, 

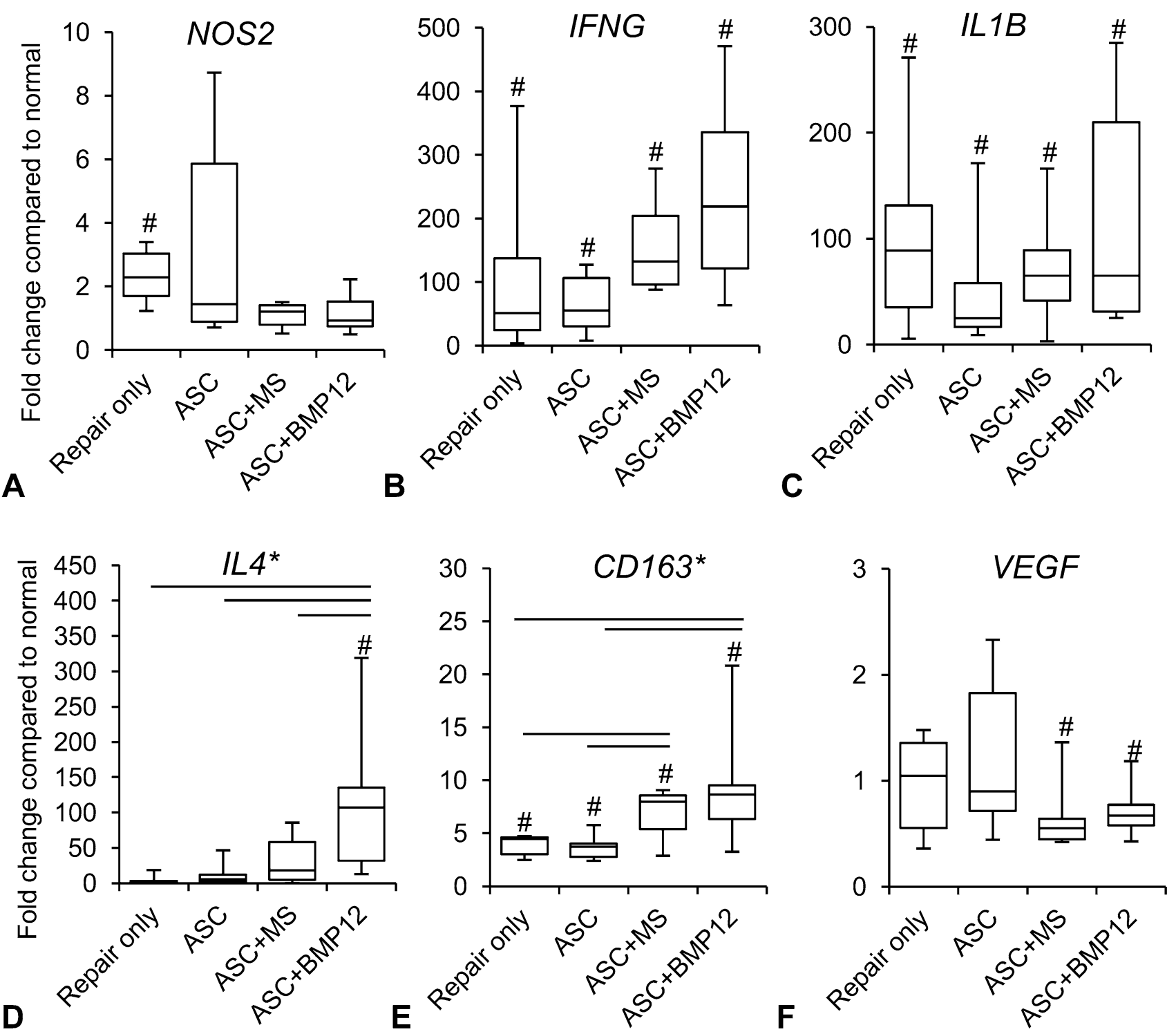

Fig. 3A-F The graphs show changes in the expression of (A) NOS2, (B) IFNG, (C) ILIB, (D) ILA, (E) CD163, and (F) VEGFA genes in the repaired tendons of indicated groups. ${ }^{*} \mathrm{p}<0.05$ among groups by one-way ANOVA; straight line $=\mathrm{p}<0.05$ between two indicated groups by Student-Newman-Keuls post hoc test; \#p $<0.05$ compared with corresponding normal tendons by paired t-test.

$0.0391 ; 95 \%$ CI, 0.0003 to $0.0779 ; p=0.049$; Fig. $3 F$ ). At the protein level, quantitative proteomics analysis revealed changes in tendon protein expression after repair and treatments (Table 1. Supplemental material is available with the online version of $C O R R^{\mathbb{R}}$.). The relationship between protein changes and treatments was revealed via a Venn diagram (Fig. 4). Ten proteins were only changed in tendons from the ASC group; 46 proteins were uniquely modified in ASC+BMP12-treated tendons; and an additional seven proteins were altered in tendons from all three treatment groups. Database search of these proteins revealed those involved in tendon inflammatory responses (Fig. 5). CD204, an M2 macrophage marker, was increased 
by nearly twofold in tendons from the ASC group (relative protein abundance: Normal, $0.61 \pm 0.11$; ASC, $1.15 \pm$ 0.34; mean difference, -0.53 ; $95 \% \mathrm{CI},-0.97$ to -0.10 ; $\mathrm{p}$ $=0.030$ ). Annexin A1 (ANXA1), a multifunctional inflammatory regulator, was reduced by approximately $30 \%$ in all treatment groups compared with normal tendons (Fig. 5; relative protein abundance: Normal, $1.42 \pm 0.22$; ASC, $0.97 \pm 0.20 ; \mathrm{ASC}+\mathrm{MS}, 0.99 \pm 0.12 ; \mathrm{ASC}+\mathrm{BMP} 12$,

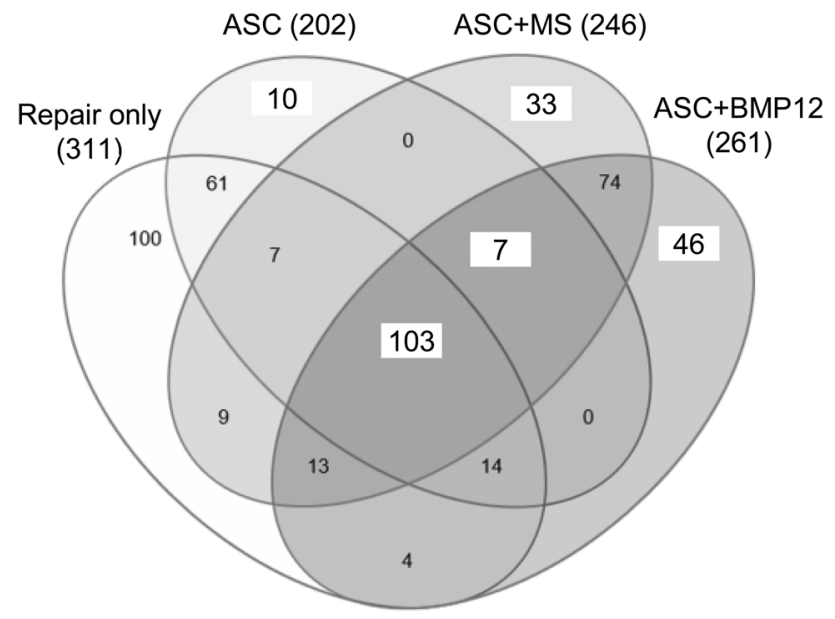

Fig. 4 The Venn diagram reveals a group relationship of proteins modified by tendon repair and indicated treatments. The numbers in the diagram designate the number of altered proteins in the indicated group(s). ASC $=$ adipose-derived mesenchymal stromal cells; $\mathrm{MS}=$ unloaded microspheres.
$0.94 \pm 0.06$; mean difference between Normal and ASC, $0.45 ; 95 \% \mathrm{CI}, 0.09$ to $0.82 ; \mathrm{p}=0.032$; mean difference between Normal and ASC+MS, $0.43 ; 95 \%$ CI, 0.12 to $0.74 ; \mathrm{p}=0.045 ;$ mean difference between Normal and ASC+BMP12, $0.47 ; 95 \% \mathrm{CI}, 0.19$ to 0.75 to; $\mathrm{p}=0.029$ ). Although ASC+BMP12 treatment induced the accumulation of tendon proinflammatory protein S100A9 (Fig. 5; relative abundance: Normal, $0.39 \pm 0.11$; ASC+BMP12: $1.99 \pm 1.34$; mean difference, $-1.60 ; 95 \% \mathrm{CI},-3.24$ to $0.04 ; \mathrm{p}=0.048)$, neutrophil cytosol factor 2 (NCF2) (Fig. 5; relative abundance: Normal: $0.70 \pm 0.09$; ASC+BMP12, $1.30 \pm 0.08$; mean difference, $-0.60 ; 95 \%$ $\mathrm{CI},-0.75$ to $-0.45 ; \mathrm{p}=0.014$ ), NCF4 (Fig. 5 ; relative abundance: Normal, $0.70 \pm 0.22$; ASC+BMP12: $1.35 \pm$ 0.20 ; mean difference, $-0.65 ; 95 \% \mathrm{CI},-1.01$ to $-0.29 ; \mathrm{p}$ $=0.011)$, and $\mathrm{TBC} 1$ domain family member 23 (TBC1D23) (Fig. 5; relative abundance: Normal, 0.92 $\pm 0.20 ;$ ASC+BMP12, $1.45 \pm 0.19$; mean difference, $-0.53,95 \% \mathrm{CI},-0.86$ to $-0.19 ; \mathrm{p}=0.027)$, the effect was counteracted by an ASC-mediated increase (50\% to 70\%) in inflammatory inhibitor prostaglandin reductase 1 (PTGR1) expression in tendons from all treatment groups (Fig. 5; relative abundance: Normal: $0.66 \pm 0.10$; ASC: $1.03 \pm 0.13 ;$ ASC+MS, $1.11 \pm 0.19 ;$ ASC+BMP12, 1.14 \pm 0.21 ; mean difference between Normal and ASC, -0.37 ; $95 \% \mathrm{CI},-0.56$ to $-0.18 ; \mathrm{p}=0.026$; mean difference between Normal and ASC+MS, $-0.45,95 \%$ CI, -0.71 to $-0.19 ; \mathrm{p}=0.013$; mean difference between normal and ASC+BMP12, $-0.49 ; 95 \% \mathrm{CI},-0.77$ to $-0.20 ; \mathrm{p}=$

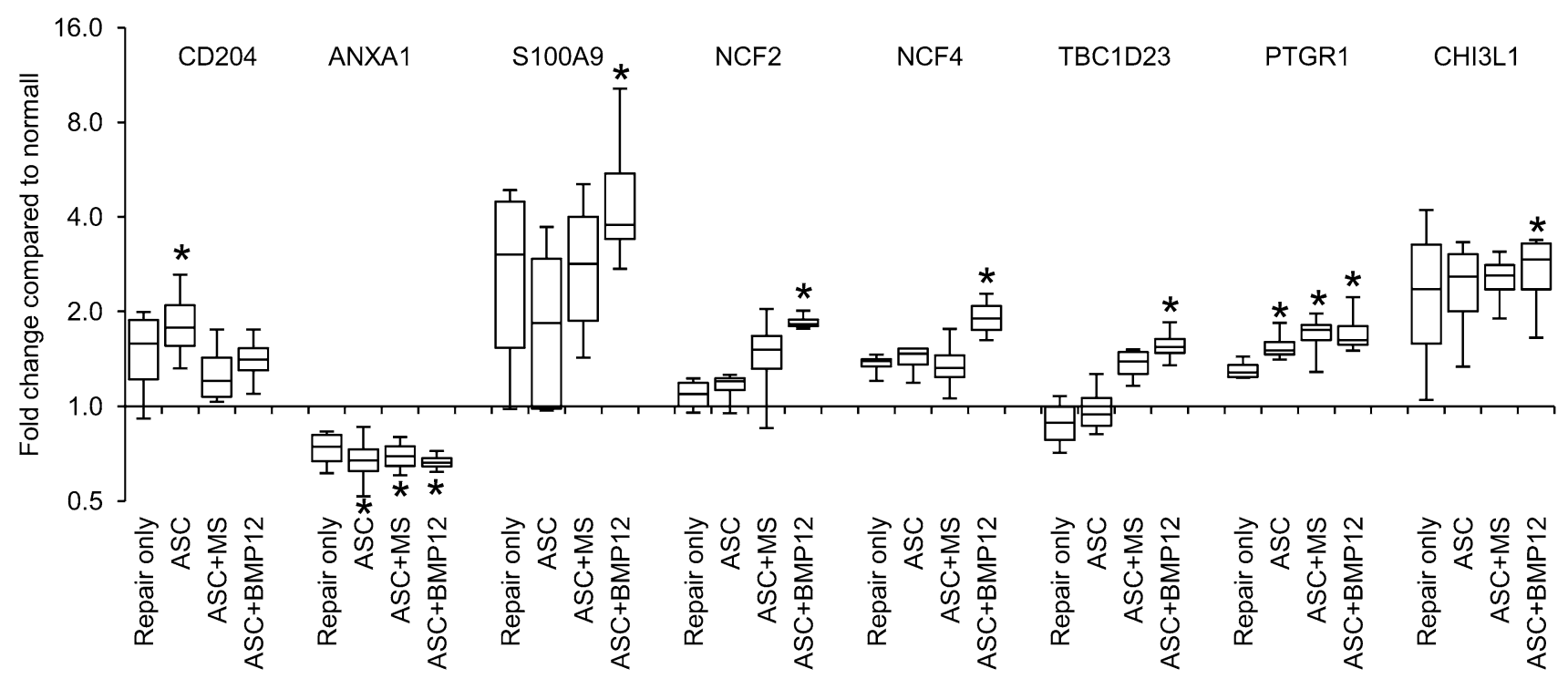

Fig. 5 The plot shows changes in relative abundance of inflammation-related proteins in flexor tendons 14 days after injury and repair. $* \mathrm{p}<0.05$ compared with normal tendons. ASC $=$ adipose-derived mesenchymal stromal cells; $\mathrm{CHI} 3 \mathrm{~L} 1$ = chitinase-3-like protein 1; MS
$=$ unloaded microspheres; $\mathrm{NCF} 2=$ neutrophil cytosol factor 2 ; NCF4 = neutrophil cytosol factor 4; PTGR1 = prostaglandin reductase 1; TBC1D23 = TBC1 Domain Family Member 23. 

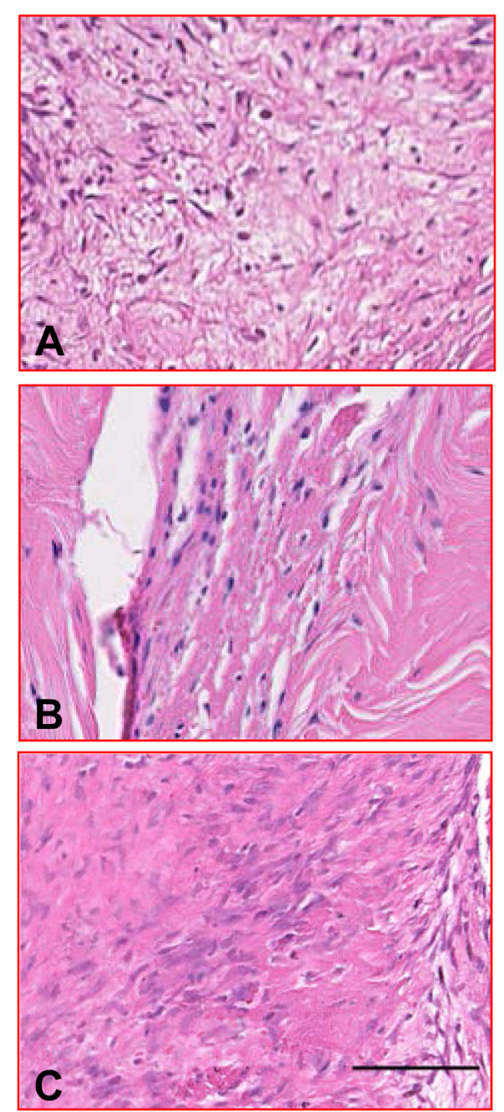

D

Fig. 6A-D The illustrations show the repair center of hematoxylin and eosin-stained flexor tendon sections from the (A) Repair only, (B) ASC, and (C) ASC+BMP12 groups; bar $=50 \mu \mathrm{m}$ long. (D) The graph shows the percentage of mononuclear cells $(\mathrm{MN})$, polymorphonuclear

0.008). Moreover, chitinase-3-like protein 1 (CHI3L1), a M2 macrophage marker and effector that positively regulates angiogenesis and tissue remodeling [24] and activates the antiapoptotic Akt signaling pathway, was enriched in BMP-12-treated tendons (Fig. 5; relative abundance: Normal, $0.45 \pm 0.09$; ASC+BMP12, $1.22 \pm 0.35$; mean difference, $-0.77 ; 95 \% \mathrm{CI},-1.22$ to $-0.32 ; \mathrm{p}=0.041)$. Semiquantitative histologic assessment (Fig. 6) revealed a reduction in mononuclear cell population at the repair site of ASC-treated tendons (Fig. 6B and D) compared with nontreated tendons (Fig. 6A and D) (Repair only: $31 \% \pm$ $1 \%$; ASC: $19 \% \pm 6 \%$; mean difference, $13 \%$; $95 \% \mathrm{CI}$, $5 \%-20 \% ; \mathrm{p}=0.021$ ). A trend of reduced mononuclear cell infiltration also was detected in ASC+BMP12-treated tendons $(22 \% \pm 4 \%$; mean difference between Repair only and ASC+BMP12, 9\%; 95\% CI, 4\%-14\%; $\mathrm{p}=0.059$; Fig. 6C-D). Collectively, while the gene expression, proteomics, and histologic analyses revealed the presence of a moderate inflammatory response in this stage of healing, current results support the conclusions that there are antiinflammatory effects primarily induced by ASCs. cells $(\mathrm{PMN})$, and fibroblastlike cells (FB) at the repair site of flexor tendons from the indicated repair groups. ASC = adipose-derived mesenchymal stromal cells. ${ }^{*} \mathrm{p}<0.05$ compared with Repair only group.

Modulation of Proliferative and Remodeling Responses by ASCs and BMP-12

The combined administration of ASCs and BMP-12, by promoting cell accumulation and matrix remodeling at the tendon repair site, accelerated the proliferative stage of tendon repair. At the mRNA level, there was a twofold increase in the expression of proliferative gene CCND1, regardless of treatment (Fig. 7A; paired normal: $0.0396 \pm$ 0.0179 ; Repair only: $0.0820 \pm 0.0126$; mean difference, $-0.0423 ; 95 \% \mathrm{CI},-0.0690$ to $-0.0157 ; \mathrm{p}=0.010$; paired normal: $0.0507 \pm 0.0166$; ASC: $0.0846 \pm 0.0141$; mean difference, $-0.0339 ; 95 \% \mathrm{CI},-0.0557$ to $-0.0122 ; \mathrm{p}=$ 0.010; paired normal: $0.0438 \pm 0.0164$; ASC+MS: 0.0811 \pm 0.0146 ; mean difference, $-0.0373 ; 95 \% \mathrm{CI},-0.0586$ to $-0.0160 ; \mathrm{p}=0.006$; paired normal: $0.0429 \pm 0.0087$; ASC+BMP12: $0.0795 \pm 0.0154 ;$ mean difference, $-0.0366 ; 95 \% \mathrm{CI},-0.0617$ to $-0.0116 ; \mathrm{p}=0.004)$. Similarly, the tenogenic gene TNMD (Fig. 7B; paired normal: $0.0008 \pm 0.0008$; Repair only: $0.0100 \pm 0.0048$; mean difference, $-0.0092 ; 95 \% \mathrm{CI},-0.0141$ to $-0.0044 ; \mathrm{p}=$ 


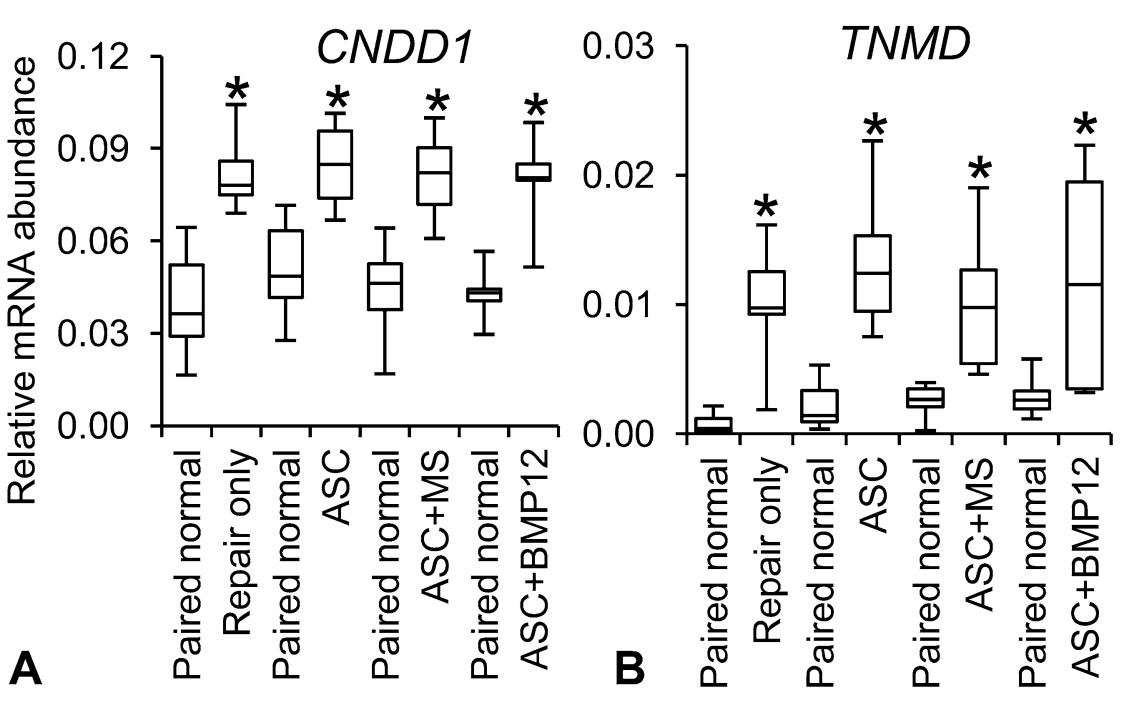

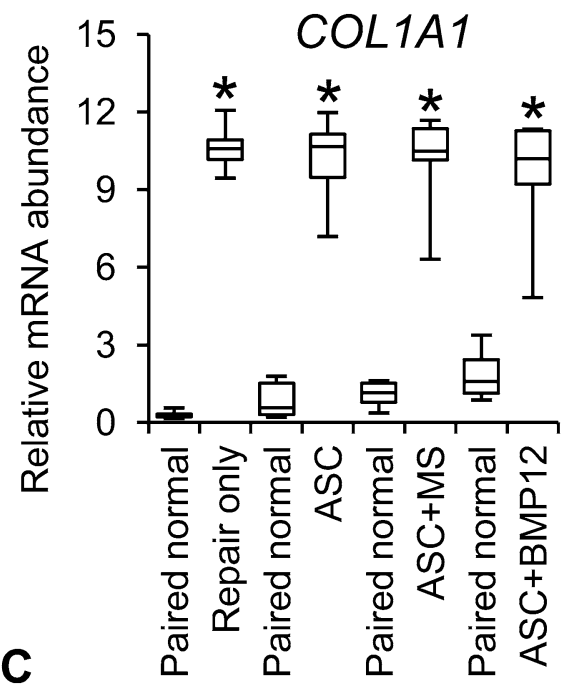

Fig. 7A-E The graphs show changes in relative mRNA abundances of (A) CCND1, (B) TNMD, (C) COL1A1, (D) COL3A1, and (E) SCX in flexor tendons of the indicated groups. ${ }^{*} \mathrm{p}<0.05$ compared with

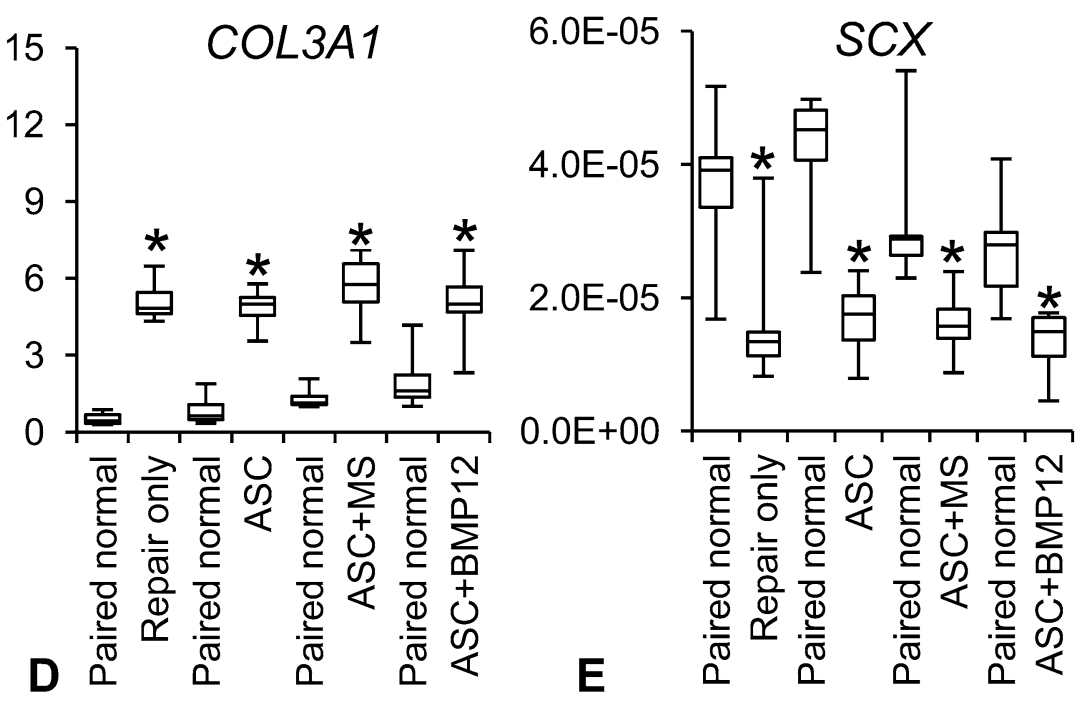

the respective paired normal. $\mathrm{ASC}=$ adipose-derived mesenchymal stromal cells; MS = unloaded microspheres.
0.004; paired normal: $0.0022 \pm 0.0020$; ASC: $0.0133 \pm$ 0.0055 ; mean difference, $-0.0111 ; 95 \% \mathrm{CI},-0.0170$ to $-0.0052 ; \mathrm{p}=0.005$; paired normal: $0.0025 \pm 0.0014$; ASC+MS: $0.0101 \pm 0.0056$; mean difference, -0.0076 ; $95 \% \mathrm{CI},-0.0136$ to $-0.0016 ; \mathrm{p}=0.002$; paired normal: $0.0029 \pm 0.0016 ;$ ASC+BMP12: $0.0119 \pm 0.0093$; median difference, $-0.0089 ; 95 \% \mathrm{CI},-0.0177$ to $-0.0001 ; \mathrm{p}=$ 0.041 ) and the matrix genes COL1A1 (Fig. 7C; paired normal: $0.30 \pm 0.15$; Repair only: $10.62 \pm 0.89$; mean difference, $-10.32 ; 95 \% \mathrm{CI},-11.27$ to $-9.38 ; \mathrm{p}=0.000$; paired normal: $0.86 \pm 0.74$; ASC: $10.14 \pm 1.74$; mean difference, $-9.28 ; 95 \% \mathrm{CI},-11.37$ to $-7.19 ; \mathrm{p}=0.000$; paired normal: $1.09 \pm 0.52$; ASC+MS: $10.10 \pm 1.97$; mean difference, $-9.01 ; 95 \% \mathrm{CI},-11.33$ to $-6.69 ; \mathrm{p}=$ 0.000; paired normal: $1.85 \pm 0.98$; ASC+BMP12: $9.50 \pm$
2.49; mean difference, $-7.65 ; 95 \% \mathrm{CI},-10.40$ to $-4.91 ; \mathrm{p}$ $=0.000$ ) and COL3Al (Fig. 7D; paired normal: $0.52 \pm$ 0.24; Repair only: $5.12 \pm 0.80$; mean difference, -4.60 ; 95\% CI, -5.59 to $-3.61 ; \mathrm{p}=0.000$; paired normal: $0.86 \pm$ 0.59; ASC: $4.85 \pm 0.77$; mean difference, -3.99 ; 95\% CI, -5.09 to $-2.88 ; \mathrm{p}=0.000$; paired normal: $1.32 \pm 0.41$; ASC+MS: $5.64 \pm 1.33$; mean difference, $-4.32 ; 95 \% \mathrm{CI}$, -5.79 to $-2.85 ; \mathrm{p}=0.002$; paired normal: $2.02 \pm 1.15$; ASC+BMP12: $4.98 \pm 1.58$; mean difference, -2.97 ; $95 \%$ $\mathrm{CI},-5.18$ to $-0.75 ; \mathrm{p}=0.019)$ were all increased by at least threefold in repaired tendons without group differences. Although COL1A1 and COL3A1 expression were both increased after tendon repair, the relative abundance of COL1Al was approximately twofold higher than that of COL3A1 in tendons from all repair groups. The expression 

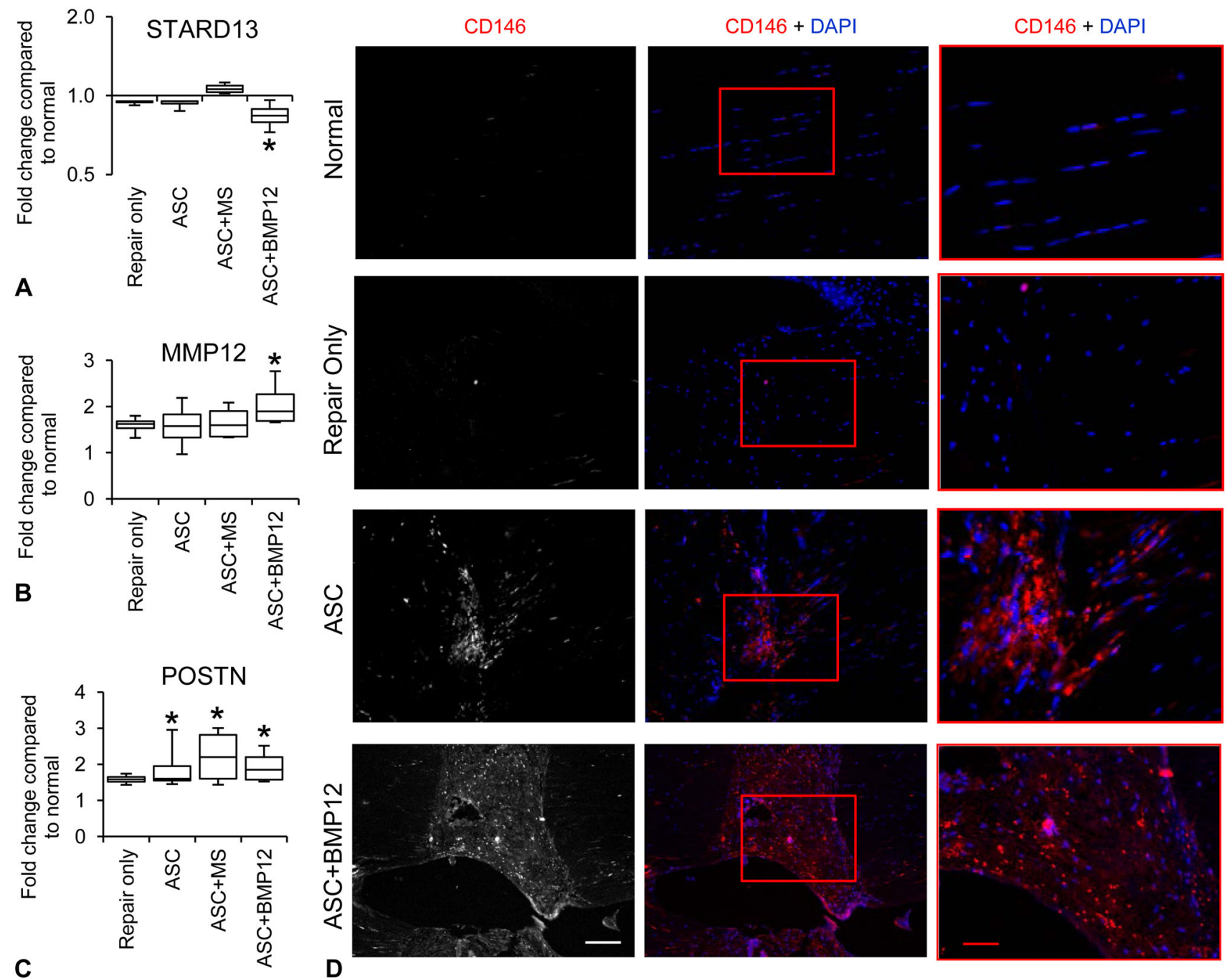

red bar $=50 \mu \mathrm{m}$ and applies to right column. ASC $=$ adipose-derived mesenchymal stromal cells; MS = unloaded microspheres; MMP12 = matrix metalloproteinase; POSTN $=$ periostin; STARD13 $=$ StARrelated lipid transfer domain protein 13 .

(A) STARD13, (B) MMP12, and (C) POSTN protein. *p $<0.05$ compared with normal tendons. (D) The illustrations show immunostaining for CD146 at the repair center of tendons from indicated groups; white scale bar $=100 \mu \mathrm{m}$ and applies to the two left columns;

of the tenogenic gene, $S C X$, was reduced by approximately $50 \%$ in all repaired tendons (Fig. 7E; paired normal: $0.000037 \pm 0.000012$; Repair only: $0.000016 \pm 0.000011$; mean difference, $0.000020 ; 95 \% \mathrm{CI}, 0.000001-0.000039 ; \mathrm{p}$ $=0.042$; paired normal: $0.000042 \pm 0.000010$; ASC: $0.000017 \pm 0.000006$; mean difference, $0.000025 ; 95 \% \mathrm{CI}$, $0.000016-0.000034 ; \mathrm{p}=0.001$; paired normal: $0.000032 \pm$ 0.000011 ; ASC+MS: $0.000016 \pm 0.000005$; mean difference, 0.000015 ; $95 \%$ CI, $0.000003-0.000028 ; \mathrm{p}=0.022$; paired normal: $0.000027 \pm 0.000008 ;$ ASC + BMP12: $0.000013 \pm 0.000005$; mean difference, $0.000014 ; 95 \% \mathrm{CI}$, $0.000004-0.000024 ; \mathrm{p}=0.017)$. Relevant to tendon cell growth and regeneration, proteomics results revealed that ASCs and BMP-12 positively modulated proteins involved in cell growth and differentiation, angiogenesis, matrix remodeling, and wound healing. Specifically, STARD13, a negative regulator of angiogenesis and cell growth, was downregulated by $20 \%$ in BMP-12-treated tendons (Fig. 8A; relative protein abundance: Normal, $1.00 \pm 0.10$; ASC+BMP12, $0.84 \pm 0.10$; mean difference, $0.16 ; 95 \%$ CI, -0.01 to $0.33 ; \mathrm{p}=0.000$ ), while MMP-12, an enzyme involved in matrix remodeling and tissue repair, was increased by twofold in repaired tendons after BMP-12 treatment (Fig. 8B; relative protein abundance: Normal, $0.54 \pm 0.14 ;$ ASC+BMP12, $1.12 \pm 0.28$; mean difference, $-0.57 ; 95 \% \mathrm{CI},-0.96$ to $-0.19 ; \mathrm{p}=0.016)$. In addition, NCF4 and CHI3L1, which are responsible for regulating angiogenesis via the VEGF signaling pathway, were enriched in BMP12-treated tendons (Fig. 5). Periostin (POSTN), a mesenchymal stem cell-secreted protein that 
supports tendon formation [26], was increased by twofold in tendons from all three treatment groups (Fig. 8C; relative protein abundance: Normal, $0.58 \pm 0.03$; ASC, $1.11 \pm$ $0.41 ; \mathrm{ASC}+\mathrm{MS}, 1.29 \pm 0.46 ; \mathrm{ASC}+\mathrm{BMP} 12,1.13 \pm 0.27$; mean difference between Normal and ASC, -0.53 ; $95 \%$ $\mathrm{CI},-1.03$ to $-0.02 ; \mathrm{p}=0.035$; mean difference between Normal and ASC+MS, $-0.71 ; 95 \% \mathrm{CI},-1.27$ to $-0.15 ; \mathrm{p}$ $=0.013 ;$ mean difference between Normal and ASC+BMP12, $-0.54 ; 95 \% \mathrm{CI},-0.88$ to $-0.21 ; \mathrm{p}=$ 0.026). At the tissue level, semiquantitative assessment of hematoxylin and eosin-stained tendon sections (Fig. 6) revealed a trend toward increased numbers of fibroblastlike cells in ASC+BMP12-treated tendons (Fig. 6C and D;) compared with nontreated tendons (Fig. 6A and D) (Repair only: $66 \% \pm 2 \%$; ASC+BMP12: $74 \% \pm 5 \%$; mean difference, $-8 \% ; 95 \% \mathrm{CI},-15 \%$ to $-1 \% ; \mathrm{p}=0.057)$. Accompanied with this trend, an improvement in tendon matrix density was observed at the repair site of ASC- and ASC+BMP12-treated tendons (Fig. 6B-C) compared with nontreated tendons (Fig. 6A). Moreover, immunostaining for CD146 (a marker of tendon stem cells) revealed that ASC and ASC+BMP12 treatment induced the accumulation of CD146-positive cells at the repair site of treated tendons (Fig. 8D). These results support the conclusions that there are antiinflammatory effects induced by ASCs and proregenerative effects induced by ASC and BMP-12 in combination.

\section{Discussion}

Tendon healing progresses through stages of inflammation, proliferation, extracellular matrix formation, and extracellular matrix remodeling $[19,36]$. Prior experiments have shown that there is a dramatic upregulation of inflammatory factors (eg, IL-1 $\beta$ ) in the earliest (ie, inflammatory) stage of tendon healing [20,30]. Although low levels of inflammatory cytokines are necessary to attract fibroblasts to the repair site $[12,20]$, a marked inflammatory response after tendon suture has been identified as a key factor leading to highly variable clinical outcomes $[10,13,20,21,40]$. One novel treatment approach to modulate inflammation is via ASCs, which were found to suppress the most-deleterious effects of macrophages by inducing a phenotypic switch from a proinflammatory M1 phenotype to an antiinflammatory M2 phenotype $[21,30]$. Furthermore, ASCs have the potential to differentiate into tendon fibroblasts and enhance matrix synthesis and remodeling $[19,29]$. Therefore, the purpose of the current study was to evaluate the effects of ASCs and the tendon growth and differentiation factor BMP-12 on inflammation, proliferation, and remodeling on tendon healing in a clinically relevant intrasynovial flexor tendon model.
There are several limitations to the current study. First, owing to our focus on the proliferative stage of repair, only one time was evaluated. It remains inconclusive whether the inflammation-modulating effects of ASCs and the tendon cell and matrix-stimulating effects of the combined treatment with ASC and BMP-12 will lead to long-term structural and functional benefits to the tendon repair. Therefore, a followup study that focuses on tendon functional outcomes (tendon strength and ROM) during the remodeling stage of healing (eg, 6 or 8 weeks after repair) will be done to determine the potential of the approach for clinical translation. Second, the mechanisms by which ASC treatment promoted the M2 macrophage phenotype were not explored in the current study. Similarly, the precise mechanism by which combined treatment with ASCs and BMP-12 achieved a beneficial effect on repair at this interval was not explored. Experiments using in vitro culture and/or small animal models should be pursued to explore the mechanism(s) of action. Third, the current study did not include all possible combinations of ASC and growth factor administration. For instance, the isolated applications of ASCs and BMP-12 with the cell-sheet delivery system were not explored. Therefore, it is not possible to attribute certain outcomes to BMP-12 alone versus BMP-12 plus ASCs.

The study showed that autologous ASCs and recombinant BMP-12 could be effectively delivered to an intrasynovial flexor tendon repair without adverse effects. Implanted ASCs were present along the repair surface and in the repair site 14 days after tendon transection and suture and these cells modulated tendon healing. These results establish the safety and effectiveness of the approach, motivating comprehensive future studies on long-term functional effects leading to clinical translation.

Consistent with the anticipated antiinflammatory effect reported previously [30], ASCs modulated the inflammatory response after intrasynovial tendon injury. Specifically, ASC-sheet treatment led to increases in regenerative M2 macrophage markers such as CD204 and antiinflammatory factor PTGR1. Histologic analysis revealed that, compared with nontreated tendons, ASCsheet treatment reduced mononuclear cells at the repair site. In addition, ASC-sheet treatment introduced CD146+ cells to the tendon repair site and led to an increase in POSTN, a stem cell-secreted factor involved in tendon formation [26]. Taken together, these data support the concept that ASCs accelerate the progression of tendon healing from the inflammatory stage into the proliferative stage of repair by simultaneously suppressing inflammation and promoting tendon cell and matrix regeneration.

The combined application of autologous ASCs and rBMP-12 modulated the proliferative and remodeling 
responses after intrasynovial tendon injury and repair, specifically affecting tendon cell proliferation and matrix synthesis. Studies have shown the potential of growth factor application in enhancing tendon repair $[18,19,25,28,29,34,35,41]$. Exogenous administration of selected growth factors to the repair site of sutured tendons (eg, platelet-derived growth factor, BMP-12) either stimulated biologic activity and/or reduced adhesions under ideal conditions [11, 29, 35, 37]. Positive outcomes, however, were limited owing to an inflammatory reaction caused by the polymer-based scaffolds that were used as carriers [10]. In the current study, the combined administration of ASCs and BMP-12 brought about increases in IL4 and CD163 expression and led to increases in the accumulation of CD146+ cells at the repair site of treated tendons. STARD13, a negative regulator of angiogenesis and cell growth, was decreased in BMP-12-treated tendons, and MMP-12, an enzyme involved in matrix remodeling and tissue repair, was increased in treated tendons. Moreover, we observed increased cellularity and improved tendon matrix accrual with combined administration of ASCs and BMP-12. These findings indicate that BMP-12 may compliment ASCs, accelerating matrix synthesis and promoting regeneration. However, as the study design did not include a BMP-12-only group, it remains unclear whether BMP-12 is effective on its own or if the addition of ASCs is necessary for the outcomes observed.

Prior reports have described an endogenous population of tendon stem cells [2], the enrichment of which can lead to improved tendon-healing outcomes [17, 18]. In the current study, the stem cell marker CD146 was upregulated in all ASC-treated groups, showing the potential for this approach to enhance intrasynovial flexor tendon regeneration. This result reveals the potential for ASC and BMP-12 therapy to induce regenerative healing by promoting differentiation and/or recruitment of progenitor cells at the repair site. However, the origin of the CD146-positive cells in the current study remains unclear. Furthermore, whether these cells will drive regenerative healing requires evaluation at longer times.

Cell- and growth factor-based therapies have great potential to influence the clinical care of tendon injuries, and intrasynovial flexor tendon repairs in particular. A novel microsphere-based delivery system was incorporated in our cell sheet approach for enhanced tendon healing. This platform can be used to deliver any cell type and/or growth factor to the intrasynovial flexor tendon repair site. Positive safety outcomes and biologic effects were seen in a clinically relevant large animal model. Our results should motivate future animal studies to evaluate the efficacy of the approach for improving tendon structural and functional properties and ultimately translating the approach to patient care.
Acknowledgment We thank Phuong N. Dang PhD, (Department of Biomedical Engineering, Case Western Reserve University, Cleveland, OH, USA) for providing the microspheres used in this study.

\section{References}

1. Archambault J, Tsuzaki M, Herzog W, Banes AJ. Stretch and interleukin-1beta induce matrix metalloproteinases in rabbit tendon cells in vitro. J Orthop Res. 2002;20:36-39.

2. Bi Y, Ehirchiou D, Kilts TM, Inkson CA, Embree MC, Sonoyama W, Li L, Leet AI, Seo BM, Zhang L, Shi S, Young MF. Identification of tendon stem/progenitor cells and the role of the extracellular matrix in their niche. Nat Med. 2007;13:1219-1227.

3. Boyer MI, Goldfarb CA, Gelberman RH. Recent progress in flexor tendon healing: the modulation of tendon healing with rehabilitation variables. $J$ Hand Ther. 2005;18:80-85; quiz 86.

4. Boyer MI, Strickland JW, Engles D, Sachar K, Leversedge FJ. Flexor tendon repair and rehabilitation: state of the art in 2002. Instr Course Lect. 2003;52:137-161.

5. Cundiff JK, McConnell EJ, Lohe KJ, Maria SD, McMahon RJ, Zhang Q. Sensing small changes in protein abundance: stimulation of Caco-2 cells by human whey proteins. J Proteome Res. 2016;15:125-143.

6. Dang PN, Solorio LD, Alsberg E. Driving cartilage formation in high-density human adipose-derived stem cell aggregate and sheet constructs without exogenous growth factor delivery. Tissue Eng Part A. 2014;20:3163-3175.

7. Gelberman RH, Amiel D, Harwood F. Genetic expression for type I procollagen in the early stages of flexor tendon healing. $J$ Hand Surg Am. 1992;17:551-558.

8. Gelberman RH, Boyer MI, Brodt MD, Winters SC, Silva MJ. The effect of gap formation at the repair site on the strength and excursion of intrasynovial flexor tendons: an experimental study on the early stages of tendon-healing in dogs. J Bone Joint Surg Am. 1999;81:975-982.

9. Gelberman RH, Khabie V, Cahill CJ. The revascularization of healing flexor tendons in the digital sheath: a vascular injection study in dogs. J Bone Joint Surg Am. 1991;73:868-881.

10. Gelberman RH, Shen H, Kormpakis I, Rothrauff B, Yang G, Tuan RS, Xia Y, Sakiyama-Elbert S, Silva MJ, Thomopoulos S. Effect of adipose-derived stromal cells and BMP12 on intrasynovial tendon repair: a biomechanical, biochemical, and proteomics study. J Orthop Res. 2016;34:630-640.

11. Gelberman RH, Thomopoulos S, Sakiyama-Elbert SE, Das R, Silva MJ. The early effects of sustained platelet-derived growth factor administration on the functional and structural properties of repaired intrasynovial flexor tendons: an in vivo biomechanic study at 3 weeks in canines. J Hand Surg Am. 2007;32:373-379.

12. Gelberman RH, Vandeberg JS, Manske PR, Akeson WH. The early stages of flexor tendon healing: a morphologic study of the first fourteen days. J Hand Surg Am. 1985;10:776-784.

13. Gotoh M, Hamada K, Yamakawa H, Yanagisawa K, Nakamura M, Yamazaki $\mathrm{H}$, Inoue A, Fukuda $\mathrm{H}$. Interleukin-1-induced glenohumeral synovitis and shoulder pain in rotator cuff diseases. J Orthop Res. 2002;20:1365-1371.

14. Heberle H, Meirelles GV, da Silva FR, Telles GP, Minghim R. InteractiVenn: a web-based tool for the analysis of sets through Venn diagrams. BMC Bioinformatics. 2015;16:169.

15. Khan U, Kakar S, Akali A, Bentley G, McGrouther DA. Modulation of the formation of adhesions during the healing of injured tendons. J Bone Joint Surg Br. 2000;82:1054-1058.

16. Khanna A, Friel M, Gougoulias N, Longo UG, Maffulli N. Prevention of adhesions in surgery of the flexor tendons of the hand: what is the evidence? Br Med Bull. 2009;90:85-109. 
17. Lee CH, Lee FY, Tarafder S, Kao K, Jun Y, Yang G, Mao JJ. Harnessing endogenous stem/progenitor cells for tendon regeneration. J Clin Invest. 2015;125:2690-2701.

18. Lee CH, Shah B, Moioli EK, Mao JJ. CTGF directs fibroblast differentiation from human mesenchymal stem/stromal cells and defines connective tissue healing in a rodent injury model. J Clin Invest. 2010;120:3340-3349.

19. Linderman SW, Gelberman RH, Thomopoulos S, Shen H. Cell and biologic-based treatment of flexor tendon injuries. Oper Tech Orthop. 2016;26:206-215.

20. Manning CN, Havlioglu N, Knutsen E, Sakiyama-Elbert SE, Silva MJ, Thomopoulos S, Gelberman RH. The early inflammatory response after flexor tendon healing: a gene expression and histological analysis. J Orthop Res. 2014;32:645-652.

21. Manning CN, Martel C, Sakiyama-Elbert SE, Silva MJ, Shah S, Gelberman RH, Thomopoulos S. Adipose-derived mesenchymal stromal cells modulate tendon fibroblast responses to macrophage-induced inflammation in vitro. Stem Cell Res Ther. 2015;6:74.

22. Matthews P, Richards H. Factors in the adherence of flexor tendon after repair: an experimental study in the rabbit. $J$ Bone Joint Surg Br. 1976;58:230-236.

23. May EJ, Silfverskiold KL. Rate of recovery after flexor tendon repair in zone II: a prospective longitudinal study of 145 digits. Scand J Plast Reconstr Surg Hand Surg. 1993;27:89-94.

24. Murray PJ, Wynn TA. Protective and pathogenic functions of macrophage subsets. Nat Rev Immunol. 2011;11:723-737.

25. Nixon AJ, Watts AE, Schnabel LV. Cell- and gene-based approaches to tendon regeneration. J Shoulder Elbow Surg. 2012;21:278-294.

26. Noack S, Seiffart V, Willbold E, Laggies S, Winkel A, ShahabOsterloh S, Flörkemeier T, Hertwig F, Steinhoff C, Nuber UA, Gross G, Hoffmann A. Periostin secreted by mesenchymal stem cells supports tendon formation in an ectopic mouse model. Stem Cells Dev. 2014;23:1844-1857.

27. Reference Genome Group of the Gene Ontology Consortium. The Gene Ontology's Reference Genome Project: a unified framework for functional annotation across species. PLoS Comput Biol. 2009;5:e1000431.

28. Schmidt CC, Georgescu HI, Kwoh CK, Blomstrom GL, Engle $\mathrm{CP}$, Larkin LA, Evans CH, Woo SL. Effect of growth factors on the proliferation of fibroblasts from the medial collateral and anterior cruciate ligaments. J Orthop Res. 1995;13:184-190.

29. Shen H, Gelberman RH, Silva MJ, Sakiyama-Elbert SE, Thomopoulos S. BMP12 induces tenogenic differentiation of adipose-derived stromal cells. PLoS One. 2013;8:e77613.

30. Shen H, Kormpakis I, Havlioglu N, Linderman SW, SakiyamaElbert SE, Erickson IE, Zarembinski T, Silva MJ, Gelberman RH, Thomopoulos S. The effect of mesenchymal stromal cell sheets on the inflammatory stage of flexor tendon healing. Stem Cell Res Ther. 2016;7:144.

31. Silfverskiold KL, May EJ. Gap formation after flexor tendon repair in zone II: results with a new controlled motion programme. Scand J Plast Reconstr Surg Hand Surg. 1993;27:263268.

32. Solorio LD, Dhami CD, Dang PN, Vieregge EL, Alsberg E. Spatiotemporal regulation of chondrogenic differentiation with controlled delivery of transforming growth factor- $\beta 1$ from gelatin microspheres in mesenchymal stem cell aggregates. Stem Cells Transl Med. 2012;1:632-639.

33. Solorio LD, Vieregge EL, Dhami CD, Dang PN, Alsberg E. Engineered cartilage via self-assembled hMSC sheets with incorporated biodegradable gelatin microspheres releasing transforming growth factor- $\beta 1 . \quad J$ Control Release. 2012;158:224-232.

34. Spindler KP, Dawson JM, Stahlman GC, Davidson JM, Nanney LB. Collagen expression and biomechanical response to human recombinant transforming growth factor beta (rhTGF-beta2) in the healing rabbit MCL. J Orthop Res. 2002;20:318-324.

35. Thomopoulos S, Das R, Silva MJ, Sakiyama-Elbert S, Harwood FL, Zampiakis E, Kim HM, Amiel D, Gelberman RH. Enhanced flexor tendon healing through controlled delivery of PDGF-BB. $J$ Orthop Res. 2009;27:1209-1215.

36. Thomopoulos S, Parks WC, Rifkin DB, Derwin KA. Mechanisms of tendon injury and repair. J Orthop Res. 2015;33:832-839.

37. Thomopoulos S, Zaegel M, Das R, Harwood FL, Silva MJ, Amiel D, Sakiyama-Elbert S, Gelberman RH. PDGF-BB released in tendon repair using a novel delivery system promotes cell proliferation and collagen remodeling. J Orthop Res. 2007;25:13581368.

38. Tsuzaki M, Bynum D, Almekinders L, Yang X, Faber J, Banes AJ. ATP modulates load-inducible IL-1beta, COX 2, and MMP-3 gene expression in human tendon cells. $J$ Cell Biochem. 2003;89:556-562.

39. Tsuzaki M, Guyton G, Garrett W, Archambault JM, Herzog W, Almekinders L, Bynum D, Yang X, Banes AJ. IL-1 beta induces COX2, MMP-1, -3 and -13, ADAMTS-4, IL-1 beta and IL-6 in human tendon cells. J Orthop Res. 2003;21:256-264.

40. Voloshin I, Gelinas J, Maloney MD, O'Keefe RJ, Bigliani LU, Blaine TA. Proinflammatory cytokines and metalloproteases are expressed in the subacromial bursa in patients with rotator cuff disease. Arthroscopy. 2005;21:1076.e1-1076.e9.

41. Woo SL, Smith DW, Hildebrand KA, Zeminski JA, Johnson LA. Engineering the healing of the rabbit medial collateral ligament. Med Biol Eng Comput. 1998;36:359-364.

42. Yamamoto M, Ikada Y, Tabata Y. Controlled release of growth factors based on biodegradation of gelatin hydrogel. J Biomater Sci Polym Ed. 2001;12:77-88 .

43. Yang G, Im HJ, Wang JH. Repetitive mechanical stretching modulates IL-1beta induced COX-2, MMP-1 expression, and PGE2 production in human patellar tendon fibroblasts. Gene. 2005;363:166-172.

44. Zhao C, Amadio PC, Paillard P, Tanaka T, Zobitz ME, Larson $\mathrm{DR}$, An KN. Digital resistance and tendon strength during the first week after flexor digitorum profundus tendon repair in a canine model in vivo. J Bone Joint Surg Am. 2004;86:320-327.

45. Zhao C, Ozasa Y, Reisdorf RL, Thoreson AR, Jay GD, An KN, Amadio PC. CORR (R) ORS Richard A. Brand Award for Outstanding Orthopaedic Research: Engineering flexor tendon repair with lubricant, cells, and cytokines in a canine model. Clin Orthop Relat Res. 2014;472:2569-2578. 